\title{
A PERMANÊNCIA NO ENSINO MÉDIO BRASILEIRO E SUA RELAÇ̃̃O COM A FORMAÇÃO DOCENTE
}

Hildegard Susana Jung

Paulo Fossatti

Edite Maria Sudbrack ${ }^{*}$

\section{PRIMEIRAS PALAVRAS}

O ensino médio brasileiro tem voltado à mídia ultimamente, principalmente depois do anúncio dos resultados do Índice de Desenvolvimento da Educação Básica (Ideb) de 2015, que ocorreu no segundo semestre de 2016. Esse índice foi criado pelo Instituto Nacional de Estudos e Pesquisas Educacionais Anísio Teixeira (Inep) no ano de 2007 e é calculado levando em conta dois indicadores: o fluxo escolar e as médias de desempenho nas avaliações (dados sobre aprovação do Censo Escolar e médias de desempenho nas avaliações do Inep, o Sistema de Avaliação da Educação Básica (Saeb) - para as unidades da federação e para o país, e a Prova Brasil - para os municípios) (INEP, 2015).

Outros dados preocupantes são os números relativos à inclusão e permanência dos jovens de 15 a 17. Segundo o observatório do Plano Nacional de Educação (PNE) ${ }^{1}$, cuja meta 3 previa a universalização da última etapa da educação básica até o ano de 2016, ainda não foi possível tal proeza. Os números deste órgão indicam que somente $61,4 \%$ dos jovens desta faixa etária encontram-se matriculados no ensino médio (dados de 2014). Apesar de 82,6\% estarem estudando, há distorção quanto à idade-série devido às reprovações, que são em alto número, fazendo com que parte dos jovens que deveriam estar no ensino médio ainda estejam no ensino fundamental. Quanto à permanência, de todas as etapas da educação básica é no ensino médio que o abandono se mostra mais expressivo, como divulgado nas taxas de evasão: a) anos iniciais: 1\%; b) anos finais: 3,2\%; ensino médio: 6,8\% (INEP, 2015).

\footnotetext{
${ }^{(*)}$ Hildegard Susana Jung. Doutoranda em Educação no Centro Universitário La Salle, Campus Canoas; bolsista Prosup/Capes. E-mail: hildegardsjung@gmail.com.

Paulo Fossatti. Doutor em Educação pela Pontifícia Universidade Católica do Rio Grande do Sul (PUCRS)(2009); e Pós-doutorado em Ciências da Educação e pesquisador associado da Universidade do Algarve (2011). E-mail: paulo.fossatti@unilasalle.edu.br.

Edite Maria Sudbrack. Universidade Regional Integrada do Alto Uruguai e das Missões, URI, Campus de Frederico Westphalen/RS E-mail: sudbrack@uri.edu.br.

${ }^{1}$ Mais informações em: http://www.observatoriodopne.org.br/metas-pne/3-ensino-medio. Acesso em 14.01.2017.
} 
A última etapa da educação básica conta atualmente com 28 mil escolas e 8 milhões de alunos. Quanto ao Ideb, antes mencionado, a meta era alcançar 4,3 pontos e o resultado foi de 3,7 (INEP, 2015). O ministro da Educação, Mendonça Filho, afirmou em dezembro de 2016, que uma das prioridades do ministério será a reformulação do ensino médio. Segundo ele, os resultados demonstram a "falência do ensino médio brasileiro e a necessidade de mudanças imediatas"2.

Desta maneira, em 26 de setembro de 2016 foi lançada a Medida Provisória 746 (MP 746/2016), instituindo a Política de Fomento à Implementação de Escolas de ensino médio em Tempo Integral. A MP altera a Lei de Diretrizes e Bases (LDB 9.394/1996) e a Lei do Fundo de Manutenção e Desenvolvimento da Educação Básica e de Valorização dos Profissionais da Educação (Fundeb)(Lei 11494/2007)(BRASIL, 2016). Antes dessa medida provisória, outros dispositivos legais já foram utilizados para lançar mão de estratégias que pudessem melhorar a permanência e a qualidade do ensino médio. Uma delas é o Projeto Ensino Médio Inovador (ProEMI), de 2013, que visava articular duas ações estratégicas: o redesenho curricular e a formação continuada de professores do ensino médio, com início no primeiro semestre de 2014 . O redesenho curricular visava ao oferecimento de uma educação de qualidade com foco na formação humana integral. Segundo o portal do MEC, o programa pretendia que as escolas elaborassem um "Projeto de Redesenho Curricular (PRC) na perspectiva da integração curricular, articulando as dimensões do trabalho, da ciência, da cultura e da tecnologia, conforme as Diretrizes Curriculares Nacionais para o Ensino Médio" (BRASIL, 2013a).

Neste cenário, o objetivo desta pesquisa consiste em analisar estratégias de permanência dos estudantes, relacionadas à formação continuada dos docentes. Seria a formação continuada docente uma técnica válida para a contenção da evasão e, consequentemente, aumentar a permanência dos estudantes na última etapa da educação básica? Uma forma de incentivar essa formação continuada foram as jornadas de formação do Pacto Nacional do Ensino Médio, sobre o qual temos dados empíricos $^{3}$ com a representação dos docentes de duas escolas gaúchas. Dentre esses mesmos professores, uma grande parcela decidiu não participar da pesquisa, não respondendo aos questionários. O que diz a voz dos silêncios? Teria a descontinuidade das políticas educacionais algo a ver com a descontinuidade das políticas educacionais? Sobre estas e outras questões convidamos o leitor a debater.

\footnotetext{
${ }^{2}$ Notícia disponível na íntegra na página web da União Nacional dos Dirigentes Municipais de educação (Undime): https://undime.org.br/noticia/09-09-2016-09-27-mec-divulga-resultados-do-ideb-2015. Acesso em 14.01.2017.

${ }^{3}$ A participação dos sujeitos por intermédio da resposta aos questionários semiestruturados foi autorizada pelo comitê de ética da universidade envolvida, por meio do parecer CEP 1.169.199.
} 
A metodologia, portanto, tem cunho bibliográfico - incluindo documentos legais - mas carrega também dados empíricos de uma pesquisa de pós-graduação stricto sensu realizada por uma das autoras, em nível de Mestrado, sobre os efeitos do Pacto Nacional do Ensino Médio. Para este artigo, trazemos a representação docente quanto à qualidade dos encontros e sobre a possibilidade de seu trabalho influenciar as taxas de permanência.

Nesta perspectiva, após a breve contextualização do tema ensino médio e de seus des(caminhos) como última etapa da educação básica brasileira, descrevemos e analisamos de maneira mais pormenorizada algumas estratégias, voltadas para a formação docente, das quais o governo lançou mãos nos últimos anos para melhorar o ensino médio. Tendo em vista o atendimento da meta 3 do PNE, antes citada, a qual versa sobre a inclusão e também visa a atacar o problema da permanência, várias políticas têm sido pensadas. Na sequência, ponderamos a formação continuada como uma dessas estratégias. A experiência do Pacto Nacional do Ensino Médio consistiu em uma tentativa de oferecer jornadas de formação visando à melhora da aprendizagem dos alunos.

\section{A LUTA PELA INCLUSÃO-E PERMANÊNCIA}

A jovem história da universalização da também recente educação básica brasileira pós Constituição de 1988 e com a nova LDB, tem alcançado grandes conquistas. Pese a que caminhe descompassadamente devido ao seu já característico caráter de descontinuidade, o Brasil luta para escolarizar seus cidadãos, pelo menos até os 17 anos de idade. O desafio de incluir nesta empreitada os 932 mil adolescentes (MEC, 2016) de 17 anos que estão fora da escola tem recebido atenção não somente de parte da União, como também de organismos multilaterais. Além da inclusão, outro problema tem merecido a atenção de todos: o abandono escolar, que no ano de 2015 alcançou a cifra de 6,8\%. Como se não bastasse, os resultados do último Ideb, como já comentamos, tinham a meta era alcançar 4,3 pontos e o resultado foi de 3,7 (INEP, 2015).

O tema da permanência no ensino médio tem tido historicamente espaço na agenda das Políticas Educacionais, ainda que não atacado de forma veemente. Segundo dados do Instituto Brasileiro de Geografia e Estatística (IBGE), somente 40,3\% dos jovens de 14 anos de idade ou mais possuem escolaridade em nível médio, o que reforça a preocupação do Estado no sentido de desenvolvimento de políticas públicas para esta etapa da educação básica (IBGE, 2013 ${ }^{4}$ ). O

\footnotetext{
${ }^{4}$ Mais dados em: <http://www.ibge.gov.br/home/estatistica/indicadores/trabalhoerendimento/pnad_continua/primeiros_ resultados/analise02.shtm>. Acesso em 15 jan. 2017.
} 
Caderno I de Formação de Professores do Ensino Médio (MEC, 2013d, p. 24), primeiro da série disponibilizada para os encontros de formação, alerta para o fato de que, no período de 1991 a 2010 "a taxa líquida de matrículas de jovens entre 15 e 17 anos no ensino médio passou de 17,3\% para 32,7\%, atingindo 44,2\% em 2004 e chegando a 50,9\% em 2009”. Contudo, registra que no Brasil existe uma "incompletude no processo de democratização da escola" (idem), uma vez que, devido ao ingresso tardio, reprovações, ou decorrente da evasão, a outra metade está ainda no ensino fundamental ou fora da escola.

Paiva e Silva (2013, p. 54) asseveram que “o ensino médio no Brasil é assombrado, desde muito tempo, pela evasão escolar", complementando que, entre os 3,6 milhões de jovens que se matriculam, somente 1,8 milhão o concluem. Kuenzer (2010, p. 857) alertou, referindo-se à democratização do acesso e à permanência, que estes fatores exigem "um novo pacto federativo, cimentado por um forte investimento, principalmente das esferas federal e estadual" (o grifo é nosso).

Neste contexto, há mais de vinte anos o governo tem lançado mão de várias políticas como estratégias para garantir a permanência dos estudantes na última etapa da educação básica. $\mathrm{Na}$ sequência faremos a descrição e análise e algumas delas, mas a ênfase especial desta pesquisa, como anunciado, está na estratégia da formação continuada de professores como potencializadora da permanência, para que a mesma não caia na vala comum das outras estratégias, hoje esquecidas. Em nosso entendimento, a formação continuada docente merece destaque, por isso é o foco desta pesquisa.

Desta maneira, podemos citar (MEC, 2016):

a) 1998: Aprovação das diretrizes do ensino médio de acordo com a nova legislação da LDB 9394/1996.

b) 2007: Criação do Fundeb com a promessa de garantir a universalização do ensino médio e lançamento do Plano de Ações Articuladas (PAR). Este instrumento para o diagnóstico da situação educacional local estava estruturado em quatro grandes dimensões: Gestão Educacional; Formação de Professores e dos Profissionais de Serviço e Apoio Escolar; Práticas Pedagógicas e Avaliação, e Infraestrutura Física e Recursos Pedagógicos (MEC, 2007).

c) 2009: Criação do Novo Exame Nacional do Ensino Médio (Enem), com objetivo de "democratizar as oportunidades de acesso às vagas federais de ensino superior, possibilitar a mobilidade acadêmica e induzir a reestruturação dos currículos do ensino médio" (MEC, 2009). As universidades passaram a optar entre quatro possibilidades de utilização do novo exame como 
processo seletivo: Como fase única, com o sistema de seleção unificada, informatizado e on-line; Como primeira fase; Combinado com o vestibular da instituição; ou Como fase única para as vagas remanescentes do vestibular (MEC, 2009).

d) 2010: Lançamento do programa Ensino Médio Inovador (ProEMI) (instituído pela Portaria 971, de 9 de outubro de 2009), um intento do Ministério da Educação no sentido de respeitar a singularidade do aluno, levando em conta suas particularidades sociais e culturais, propondo um Projeto de Redesenho Curricular (PRC), tendo como bases:

a) Carga horária mínima de 3.000 (três mil horas), entendendo-se 2.400 horas obrigatórias, acrescidas de 600 horas a serem implantadas de forma gradativa; b) Foco em ações elaboradas a partir das áreas de conhecimento, conforme proposto nas Diretrizes Curriculares Nacionais para o ensino médio e que são orientadoras das avaliações do ENEM; c) Ações que articulem os conhecimentos à vida dos estudantes, seus contextos e realidades, a fim de atender suas necessidades e expectativas, considerando as especificidades daqueles que são trabalhadores, tanto urbanos como do campo, de comunidades quilombolas, indígenas, dentre outras; d) Foco na leitura e letramento como elementos de interpretação e de ampliação da visão de mundo, basilar para todas as áreas do conhecimento [...] (BRASIL, 2013b, p. 11).

Com relação às atividades, o documento sugeria que fossem fundamentadas no processo de iniciação científica (teórico-práticas), fazendo uso de diversos laboratórios, de maneira a potencializar os saberes das diferentes áreas do conhecimento. Mencionava também o ensino das línguas estrangeiras, artes, esportes, comunicação e práticas interdisciplinares com

Atividades em Línguas Estrangeiras/Adicionais, desenvolvidas em ambientes que utilizem recursos e tecnologias que contribuam para a aprendizagem dos estudantes; g) Fomento às atividades de produção artística que promovam a ampliação do universo cultural dos estudantes; h) Fomento as atividades esportivas e corporais que promovam o desenvolvimento integral dos estudantes; i) Fomento às atividades que envolvam comunicação, cultura digital e uso de mídias e tecnologias, em todas as áreas do conhecimento; j) Oferta de ações que poderão estar estruturadas em práticas pedagógicas multi ou interdisciplinares, articulando conteúdos de diferentes componentes curriculares de uma ou mais áreas do conhecimento; k) Estímulo à atividade docente em dedicação integral à escola, com tempo efetivo para atividades de planejamento pedagógico, individuais e coletivas; 1) Consonância com as ações do Projeto Político-Pedagógico implementado com participação efetiva da Comunidade Escolar; m) Participação dos estudantes no Exame Nacional do Ensino Médio (ENEM); n) Todas as mudanças curriculares deverão atender às normas e aos prazos definidos pelos Conselhos Estaduais para que as alterações sejam realizadas (BRASIL, 2013b, p. 12).

e) 2010: O Conselho Nacional de Secretários de Educação (Consed) cria o Grupo de Trabalho da Reforma do Ensino Médio que produziu, entre outros, documentos sobre os seguintes 
temas: a) Organização Curricular e Base Nacional Comum - Mesa 1; b) Jornada Escolar ampliada e Condições de Oferta do Ensino Médio - Mesa 2; c) Formação de Professores e Gestores - Mesa 3; d) Integração do Ensino Médio com a Educação Profissional - Mesa 4; e) Instrumentos de Avaliação do Ensino Médio - Mesa 5 (CONSED, 2015). ${ }^{5}$

f) 2012: As Diretrizes Curriculares Nacionais para o Ensino Médio são aprovadas pelo Conselho Nacional de Educação (CNE).

g) 2013: Projeto de Lei 6.840/2013 (PL6.840/2013), o qual criava a Comissão Especial destinada a promover Estudos e Proposições para a Reformulação do Ensino Médio (CEENSI). Este dispositivo legal tinha a pretensão de alterar a LDB, para instituir a jornada em tempo integral no ensino médio, bem como dispor sobre a organização dos currículos do ensino médio em áreas do conhecimento (BRASIL, 2013c). Além disso, foi instituído o Pacto Nacional pelo Fortalecimento do Ensino Médio, pela Portaria 1.140, de 22 de novembro de 2013, representando a articulação e a coordenação de ações e estratégias entre a União e os governos estaduais e distrital na formulação e implantação de políticas para elevar o padrão de qualidade do ensino médio brasileiro, em suas diferentes modalidades, orientado pela perspectiva de inclusão de todos que a ele tem direito. Trazia o compromisso do MEC e das secretarias estaduais e distrital de educação pela valorização da formação continuada dos professores e coordenadores pedagógicos atuantes no ensino médio público, nas áreas rurais e urbanas, além de gestores das secretarias de educação.

h) 2014: Plano Nacional da Educação (PNE), no qual consta a Meta 3.1, com a finalidade de instituir um programa nacional de renovação do ensino médio, “a fim de incentivar práticas pedagógicas com abordagens interdisciplinares estruturadas pela relação entre teoria e prática, por meio de currículos escolares que organizem, de maneira flexível e diversificada, conteúdos obrigatórios e eletivos articulados [...]" (BRASIL, 2014).

i) 2016: Medida Provisória 746, de 22 de setembro de 2016, modificando a LDB. Entre as principais alterações, podemos citar: a) a ampliação da carga horária obrigatória de 800 para 1.400 horas; b) as disciplinas de artes, educação física, sociologia e filosofia serão incluídas (antes obrigatórias) se assim o determinar a Base Nacional Comum Curricular (BNCC), ainda em tramitação no Congresso Nacional; c) a formação técnica e profissional tem o mesmo peso das outras áreas do conhecimento (linguagens, matemática, ciências da natureza e ciências humanas); d) a língua inglesa passa a ser obrigatória em todas as escolas; e) as escolas podem contratar

\footnotetext{
${ }^{5}$ Os documentos podem ser visualizados na íntegra em: http://www.consed.org.br/reuniao/seminario-reformulacao-doensino-medio-camara-dos-deputados. Acesso em 14.01.2017.
} 
professores sem formação específica em nível superior, baseando-se em seu notório saber para trabalhar em áreas específicas (BRASIL, 2016). Apesar de aprovada pelo Congresso e a MP 746/2016 já estar em vigor, o Ministério da Educação (MEC) prevê que a primeira turma de ensino médio integral passe a operar no novo sistema em 2018 (MEC, 2016). Para sua implementação, a mesma depende de estrutura que as escolas ainda não possuem, além da BNCC que ainda está em votação no Congresso Nacionl.

Como vimos, parece não haver falta de medidas legais para a melhoria do ensino médio, ao contrário, temos um encorpado arcabouço legal, com estratégias que vão de aumento de carga horária, estabelecimento de conteúdos mínimos e optativos, até a formação continuada de professores. O que falta então? Apesar de não termos a pretensão de aprofundar-nos nesta discussão, ocorrem-nos duas suposições: a primeira diz respeito aos autores das políticas anteriormente citadas e seu conhecimento sobre os problemas da educação desde o ponto de vista do professor. Este, acreditamos, é quem melhor conhece o aluno e seu contexto, bem como seus problemas e desafios com elação à aprendizagem. A este respeito, Carneiro (2012, p. 15-17) é enfático:

É curioso como, cada vez mais, falam sobre ensino médio economistas, engenheiros, empresários e jornalistas e, cada vez menos, professores, educadores, sociólogos, antropólogos, psicólogos, etc. É como se dissessem: a estes lhes falta competência [...] Historicamente, o ensino médio foi das elites, e foi se abrindo uma concessão às classes populares, então 'não importa que seja eficiente. Importa, sim, e só, que exista!'.

Por outro lado, a julgar pela descontinuidade e descaminhos de muitas destas políticas, como é o caso do Pacto Nacional do Ensino Médio, ao qual nos dedicamos na sequência, ou da MP 746/2016, a qual depende de uma BNCC que ainda não está pronta e que não tem previsão de término, é necessário concordar que a prática de nossa legislação está distante do discurso. Neste sentido, Barbosa e Bedran (2016, p. 52) esclarecem que “a dificuldade está no exercício de seus princípios [da legislação], desenvolvendo efetivamente a condição cidadã dos sujeitos envolvidos na escola". Desta forma, percebemos que o discurso está posto, mas há uma dificuldade de assimilação do mesmo pelo ideário coletivo, o que acarreta no abandono de diversas políticas, como aconteceu com o Pacto Nacional pelo Fortalecimento do Ensino Médio.

Diante deste cenário, a formação continuada docente se apresenta como uma importante estratégia para o incremento da permanência dos estudantes - conforme elucidamos na sequência Como entende Zabala (1998), os saberes docentes influenciam na sua prática pedagógica e na sua relação com os alunos. Além disso, a complexidade da educação na contemporaneidade exige que 
os educadores e educadoras estejam preparados. Se a formação continuada e atualização permanente já são considerados essenciais em todas as profissões, por que não o seria na docência?

\section{A FORMAÇÃO CONTINUADA DOCENTE COMO ESTRATÉGIA PARA A PERMANÊNCIA}

Das estratégias citadas no item anterior, aquela que provavelmente mais diretamente se preocupou com a formação continuada de professores, foi o Pacto Nacional pelo Fortalecimento do Ensino Médio. Este tópico se dedicará especialmente a esta política por considerarmos que a permanência pode estar relacionada, em grande medida, à performance docente. Em outras palavras: acreditamos que a formação continuada docente pode ser uma estratégia eficaz no combate à evasão.

Não se trata, aqui, de concordar com as políticas de responsabilização do professor por todo o quadro caótico que se apresenta no ensino médio, as quais funcionam à base de prêmios e castigos. Nessa perspectiva, se presume que escores baixos em testes padronizados são "causados por professores e diretores preguiçosos, que precisam ser ameaçados com a perda de seus empregos" (RAVITCH, 2011, p. 132).

Em uma perspectiva diretamente oposta, consideramos que a formação continuada, quando conduzida de forma a valorizar o docente, pode auxiliar no incremento da permanência. É preciso levar em conta, antes de mais nada, que o professor é sujeito dotado de angústias, medos, preocupações e que precisa encarar, na atualidade, um ambiente cada vez mais hostil. Os docentes devem ser vistos

não como seres abstratos, ou essencialmente intelectuais, mas, como seres essencialmente sociais, com suas identidades pessoais e profissionais, imersos numa vida grupal na qual partilham uma cultura, derivando seus conhecimentos, valores e atitudes dessas relações, com base nas representações constituídas nesse processo que é, ao mesmo tempo, social e intersubjetivo (GATTI, 2003, p. 196).

A situação é complexa, posto que na outra ponta desta dinâmica está o aluno. Como atividade humana, no exercício da docência o professor, ao entrar na sala de aula, não se despe de suas concepções e valores (NÓVOA, 2009). Entendemos que estas atitudes ou a falta delas têm grande influência sobre os estudantes, como ensina Zabala (1998, p. 2):

É preciso insistir que tudo quanto fazemos em aula, por menor que seja, incide em maior ou menor grau na formação de nossos alunos. A maneira de organizar a aula, o tipo de incentivos, as expectativas que depositamos, os materiais que utilizamos, cada uma destas decisões veicula 
determinadas experiências educativas, e é possível que nem sempre estejam em consonância com o pensamento que temos a respeito do sentido e do papel que hoje em dia tem a educação.

Como anteriormente referimos, o Pacto Nacional pelo Fortalecimento do Ensino Médio, instituído pela Portaria 1.140, de 22 de novembro de 2013, representava a articulação e a coordenação de ações e estratégias entre a União e os governos estaduais e distrital na formulação e implantação de políticas para elevar o padrão de qualidade do ensino médio brasileiro, em suas diferentes modalidades, orientado pela perspectiva de inclusão de todos que a ele tem direito. Trazia o compromisso do MEC e das secretarias estaduais e distrital de educação pela valorização da formação continuada dos professores e coordenadores pedagógicos atuantes no ensino médio público, nas áreas rurais e urbanas.

Os cadernos contendo o material de formação puderam ser acessados no site do MEC e o professor que quisesse aderir à formação deveria ser cadastrado pelo diretor da escola na qual leciona. A adesão dos educadores foi realizada no Sistema Integrado de Monitoramento do Plano de Desenvolvimento da Educação (SisMédio), sistema informatizado de cadastro desenvolvido para atender ao público do Pacto. Cada docente recebeu bolsa mensal de $\mathrm{R} \$ 200^{6}$ para fazer a formação, presencial e desenvolvida na própria escola, de 200 horas anuais. Para participar, deveria atuar em sala de aula e estar registrado no Censo Escolar.

Em junho de 2015, porém, após atrasos nos repasses das bolsas, as escolas foram comunicadas de que haveria a interrupção do Pacto. Na correspondência eletrônica enviada aos formadores, com pedido de que fosse transmitido aos professores, havia a informação de que, por determinação do MEC, as atividades relacionadas ao Pacto estariam suspensas para o ano de 2015 e que em 2016 seriam retomadas, possivelmente em outro formato, priorizando as especializações, mestrados e doutorados. Ainda, informava a manifestação das secretarias, universidades e professores envolvidos pela continuidade do modelo atual, esclarecendo que esta será uma negociação junto ao MEC. A retomada não aconteceu, o que consideramos uma lástima. Gatti (2003, p. 197) salienta a importância da formação continuada que acontece no próprio ambiente de trabalho: "O que é preciso conseguir é uma integração na ambiência de vida e trabalho daqueles que participarão do processo formativo".

\section{A representação dos sujeitos da pesquisa sobre as jornadas de formação do Pacto}

Como antes informamos, para a coleta dos dados empíricos foram entrevistados professores de duas escolas gaúchas, através de questionários semiestruturados. Com relação à periodicidade,

\footnotetext{
${ }^{6}$ Aproximadamente U\$80 no câmbio de janeiro de 2014.
} 
metodologia e ambiente dos encontros de formação continuada do Pacto, a totalidade dos entrevistados referiu que estes se davam com periodicidade semanal fazendo menção ao ambiente, considerado satisfatório, tanto no aspecto físico, como emocional. Sobre a metodologia utilizada, a grande maioria (86\%) a considerou adequada, variada e interessante. Na representação da totalidade dos docentes, a compensação financeira de $\mathrm{R} \$ 200,00$ mensais foi considerada importante, referindo os baixos salários dos professores.

A teoria de Gatti (2003) de que as trocas entre os professores em seu ambiente de trabalho auxiliam em sua formação continuada se vê confirmada com estas respostas. Segundo a autora, “crenças e práticas são construídas num contexto de interação e negociação social constantes, em que o compromisso com a identidade social, normas grupais e tradições culturais têm um papel central" (p. 200).

\section{Formação continuada versus permanência na representação dos sujeitos}

Com relação à representação dos docentes a respeito da relação entre as jornadas de formação e a permanência dos estudantes (se o Pacto poderia interferir nos índices de evasão), 47\% referiram que esta tem outros motivos, mas 33\% acreditam que sim, que há relação. Entretanto, 54\% fazem uma relação direta entre o abandono escolar e a prática pedagógica. Desta maneira, podemos inferir que, embora o professor não considere que o Pacto tenha relação direta com a diminuição da evasão escolar, o docente reconhece a estreita relação entre a permanência escolar e o quefazer pedagógico, resultado da formação.

Neste sentido, Zabala (1998) explica que a formação continuada docente está diretamente relacionada ao seu desempenho e aos rumos da sua prática pedagógica. $\mathrm{O}$ autor refere que quanto maior e mais rica for a história de vida e profissional docente, maiores serão as possibilidades de o professor desempenhar uma prática educacional significativa. E a prática significativa, como sabemos, é aquela que colabora com a permanência dos estudantes, porque

educar não se limita a repassar informações ou mostrar apenas um caminho, mas é ajudar a pessoa a tomar consciência de si mesmo, dos outros e da sociedade. É oferecer várias ferramentas para que a pessoa possa escolher, entre muitos caminhos, aquele que for compatível com os seus valores, sua visão de mundo e com circunstancias adversas que cada um irá encontrar. (p. 12).

Ainda neste sentido, buscando saber se a maior ou menor adesão ao Pacto Nacional do Ensino Médio pelos docentes interfere na prática educativa, verificamos que $80 \%$ dos respondentes acreditam que os encontros de formação do Pacto podem ter relação com o aumento da qualidade do ensino, o que nos mostra que, apesar de ter sido suspensa, esta política educacional 
aparentemente caminhava para a concretização do seu maior objetivo. Interessante ponto auferido na coleta de dados empíricos é que, mesmo aqueles docentes que não consideram importantes os encontros de formação, sugeriram temas para a sua continuidade, ou seja, nenhum dos respondentes sinalizou pela não continuidade dos encontros de formação. Foram propostos temas como um trabalho prático, com oficinas, atividades interdisciplinares, projetos e sequências didáticas, e a questão das novas tecnologias e mídias.

Sobre o sentimento de participação e emancipação e/ou regulação no processo de implantação do Pacto, a maioria (87\%) dos docentes consideraram que sim, que se sentiram protagonistas, referindo também seu crescimento profissional e a oportunidade de trabalhar de forma colaborativa. Ainda assim, foi possível perceber que, quando o cidadão não participa da elaboração de uma política pública, seu envolvimento fica comprometido, pois não incorpora a ideia de vínculo (SANTOS; AVRITZER, 2002). Notamos aqui um dos limites da representatividade, onde há o grande desafio de formar a cultura da participação no pensamento coletivo (WEYH, 2011; HERBERT, 2008). Desta forma, Santos (2002), ensina que a emancipação social no modelo representativo se constitui ao mesmo tempo óbvia e inverossímil, restando-nos a utopia, mas no seu sentido relativo, o de buscar caminhos emancipatórios do colonialismo para a solidariedade.

\section{A voz dos silêncios e a descontinuidade das políticas educacionais}

A decisão pela não-participação da pesquisa por parte da maioria dos docentes de uma das escolas (somente 22,22\% concordaram em participar), desafiou-nos a buscar entender o que significa este silêncio. Sobre este assunto, anuímos com Santos (2002, p. 333) no sentido de que na arqueologia virtual do presente “a escavação interessa-se pelos silêncios”, para dali depreender novas utopias e novas possibilidades.

Várias são as hipóteses sobre o porquê do aparente desinteresse pela discussão sobre uma política educacional que, de alguma forma, mudou a rotina de todos através dos encontros de formação: a) A exaustiva jornada de trabalho dos profissionais do ensino médio, gerando cansaço físico e mental; b) A falta de credibilidade atribuída às políticas educacionais devido ao seu caráter de descontinuidade ${ }^{7}$; c) A baixa valorização do profissional docente, salarial e inclusive moral, por parte das autoridades, da sociedade em geral e própria; d) A formação precária, frágil em pressupostos teóricos e epistemológicos, dificultando o entendimento da importância de sua

\footnotetext{
${ }^{7}$ Como aconteceu com o próprio Pacto, suspenso no início de 2015, com a promessa de continuar em 2016, o que não se concretizou.
} 
participação; e) A baixa performance política, derivada possivelmente do conjunto dos fatores anteriores; f) A expressão de que a escola também representa um local de conflitos, na qual interesses de grupos contrários tensionam fortemente, influenciando inclusive as ações pedagógicas. Sobre esta última hipótese, em especial, gostaríamos de deter-nos um pouco mais profundamente a seguir, uma vez que alguns registros nos chamam a atenção.

O conflito, como forma de expressão democrática é extremamente saudável. É através de conflitos que demandas importantes de uma comunidade ganham voz e, invariáveis vezes, são atendidas através das políticas públicas. Na escola não é diferente, uma vez que, tendo como pressuposto uma gestão democrática, com eleição direta de diretores, é natural que haja o tensionamento de interesses e grupos cujas opiniões geralmente não convergem. Neste sentido, os depoimentos de dois docentes chamam nossa atenção: "infelizmente parece que existem duas escolas na mesma instituição devido à ânsia de demonstrar poder na execução de seus cargos" (DB1); “a coordenação pedagógica não tinha formação adequada para aprofundar as temáticas e possibilitar avanços práticos, concretos" (DB5), referindo-se aos gestores da escola, quando a pergunta versava sobre a questão o incentivo da interdisciplinaridade através dos encontros de formação do Pacto. Com relação ao ano de 2014, ano eleitoral marcado por uma disputa forte, o (a) DB1 comenta (a pergunta referia-se à importância da remuneração para os docentes participantes do Pacto) que alguns colegas:

ao ouvir sobre remuneração, mudaram de ideia e passaram a assistir as aulas, ao mesmo tempo em que incentivados pelo dinheiro, tornou-se algo massivo, trabalhoso e cansativo devido à carga de exercícios excessivo para se cumprir metas e a discussão foi ficando pequena devido aos posicionamentos críticos ao programa cada vez maiores conforme a eleição se aproximava (estávamos no ano eleitoral).

Do depoimento anterior inferimos que o corpo docente apresenta uma ruptura ideológica no sentido de que um grupo apoia o atual governo Federal e outros são ferrenhamente contrários, fazendo-nos apostar em uma espécie de boicote às ações da gestão, hipótese que baseamos no que segue:

Infelizmente as discussões tomavam partido e a má vontade predominou, transformando educadores em alunos, que simplesmente reproduziram respostas através do copia e cola dos computadores. Alguns educadores que se intitulam importantes devido ao cargo provisório nos setores que simplesmente assistiam as aulas, mas não faziam exercícios (DB1 - grifos nossos).

Tal atitude parece demonstrar certa confusão entre formação e militância política e formação e militância político-partidária, sendo que nesta última, o grupo opositor boicota toda e qualquer iniciativa do outro. A questão é que, em esferas mais amplas do que o cotidiano escolar, a 
situação não é muito diferente, agregando ao cenário um alto grau de complexidade. Pela lista de políticas educacionais - já citadas - idealizadas nos últimos vinte anos para melhorar a situação do ensino médio e que não tiveram continuidade, podemos verificar uma situação muito semelhante.

No caso do Rio Grande do Sul, marcado pela alternância de poder - o estado é conhecido nacionalmente como aquele que não elege sucessores -, as políticas educacionais acabam avançando pouco, e na escola a situação parece similar, como depreendemos da seguinte assertiva:

O que mais chamou atenção é que os mediadores do Pacto que também trabalhavam nos setores, curiosamente foram substituídos com a nova gestão estadual, alegando sempre a mudança devido ao posicionamento partidário. Isto é o problema geral das propostas pedagógicas, das ações e dos projetos... nada dá continuidade. Ações nacionais como esta são difíceis não pela ação e sim pelo recurso humano disposto a elaborar as atividades (DB1).

Não se trata, porém, de despolitizar a escola, mas antes disso, de entender e exercer a diferença entre formação e militância política e formação e militância político-partidária. Por outro lado, fica evidente o sentimento de não-vínculo, de não pertencimento, gerado pela maneira hegemônica com a qual o Pacto foi concebido, ainda que seja considerado pela maioria dos sujeitos como uma forma de participação. A concepção hegemônica de democracia muitas vezes acarreta em apatia política (SANTOS; AVRITZER, 2002), "um silêncio surdo" (BALL, 2011, p. 46) ou, como diria Bobbio (1986), apatia eleitoral, o que se mostra igualmente na participação desta política educacional do Pacto. Neste cenário, é possível perceber ainda o desencantamento (SANTOS, 2002) docente com relação às políticas educacionais, devido ao seu caráter de descontinuidade, e de políticas de governo em detrimento de políticas de Estado.

A formação política talvez seja uma matéria pendente em nossos cursos de formação, nas próprias pautas de formação continuada e inclusive na continuidade das políticas públicas educacionais. Temos políticas de governo em detrimento de políticas de estado. Como dizem Rocha e Salbego (2004), é preciso blindar nossa prática política de certo senso de independência, ainda que estejamos filiados a organizações, tendo como compromisso o ser humano e a verdade. Kuenzer (1999) alerta que a ideologia política deve transcender a ideologia político-partidária, no sentido de buscar um consenso que articule as propostas à sua intencionalidade e consecução.

\section{ÚLTIMAS PALAVRAS}

O ensino médio brasileiro tem sido alvo de inúmeras políticas educacionais nos últimos 20 anos, mas chama a atenção seu caráter de descontinuidade e de distância entre o discurso legal e a prática efetiva nas escolas. Talvez seja por isso que esta etapa da educação básica é aquela que 
ainda conta com as piores performances, sendo alvo de duras críticas e grande preocupação por parte das autoridades e da sociedade em geral. Sabemos que a retórica de uma política (reforma) educacional, poderá nem sempre conseguir alcançar seus propósitos, dado que tende a sofrer a influência de restrições políticas, econômicas e sociais no momento de sua implantação ou durante o seu percurso. Ainda assim, acreditamos que algumas experiências merecem ser detalhadamente avaliadas, de forma a serem melhor aproveitadas e, quem sabe, até reeditadas.

Neste contexto, consideramos a formação continuada docente como uma grande estratégia de auxílio ao incremento da permanência no ensino médio. Além da literatura sobre o assunto, após a conclusão da pesquisa, a representação dos sujeitos leva a entender que os encontros de formação do Pacto Nacional pelo Fortalecimento do Ensino Médio durante o ano de 2014, ainda que não livre de tensões, foram um aliado à elevação da qualidade da prática pedagógica no ensino médio das escolas pesquisadas, bem como à permanência. As atividades sugeridas, mesmo tendo sido propostas de maneira hegemônica, já que o docente não participou de sua formulação, dificultando o vínculo e o pertencimento, contribuíram para o sentimento de participação e emancipação, devido ao seu caráter reflexivo, numa tentativa de envolver toda a comunidade escolar como, por exemplo, a atividade do Caderno de Formação I da etapa II, que sugere a discussão em sala de aula de metas do PPP (Projeto Político-Pedagógico da escola), ou o levantamento do perfil socioeconômico dos alunos sugerido no Caderno I da Etapa I, permitindo entender melhor a sua realidade.

Da presente pesquisa podemos inferir que o trabalho colaborativo proposto pelas jornadas de formação do Pacto tem se configurado um dos maiores desafios ao docente, no sentido de entender que a escola não é mais o lócus do saber instituído (DAMIANI et. al., 2009) e que as comunidades de prática ou aprendizagens em rede (NÓVOA, 2009; SCHÖN, 1992; DEVÉS, 2003) poderão configurar-se um grande auxílio no sentido de que os educadores e educadoras consigam resgatar sua identidade, sua profissionalidade, valorização própria, da sociedade e do Estado, mobilizandose em direção à melhora da aprendizagem dos alunos, o que, seguramente, levará consigo a queda da evasão e o aumento da qualidade do ensino.

Com a conclusão da presente pesquisa, é necessário recusar "o fechamento do horizonte de expectativas e de possibilidades" (SANTOS, 2002, p. 333), contudo, seus achados representam significativos indícios de que há uma importante relação entre a formação continuada dos professores e a permanência dos alunos no ensino médio. É certo que ficam lacunas, posto que as políticas de permanência têm sido marcadas pela descontinuidade e, como no caso do Pacto Nacional pelo Fortalecimento do Ensino Médio acabam tendo uma vigência tão curta, que a própria pesquisa de seus efeitos consiste em um desafio. 
Por outro lado, novas questões podem ser postas para novas investigações, como, por exemplo, o porquê da não menção da formação continuada dos professores na nova MP 746/2016. Esta normativa, justamente pelo contrário, prescinde da formação em nível superior no caso dos professores a serem contratados pelo seu "notório saber" (BRASIL, 2016), alterando o artigo 61 da LDB, bem como a meta 15 do PNE 2014-2024. Que significado tem esta resolução de abrir mão da formação em nível superior? Qual o seu impacto nas licenciaturas das universidades?

\section{REFERENCIAS}

BALL, Stephen J. Sociologia das políticas educacionais e pesquisa crítico-social: uma revisão pessoal das políticas educacionais e da pesquisa em política educacional. In: ; MAINARDES, J. (Orgs). Políticas educacionais: questões e dilemas. São Paulo: Cortez, 2011, 288p.

BARBOSA, S.M.A.D.; BEDRAN, P.F. Discurso e relações de poder na (re) construção da identidade profissional de professores de língua em uma comunidade de prática no ambiente digital. Revista Horizontes de Linguistica Aplicada, Brasília, v. 15, n. 1, p. 117-149, 2016.

BRASIL. Medida Provisória 746, de 22 de setembro de 2016. Institui a Política de Fomento à Implementação de Escolas de Ensino Médio em Tempo Integral, altera a Lei 9.394/96, que estabelece as diretrizes e bases da educação nacional, e a Lei 11.494/2007, que regulamenta o Fundo de Manutenção e Desenvolvimento da Educação Básica e de Valorização dos Profissionais da Educação, e dá outras providências. Diário Oficial da União, 23 set. 2016, p. 01. Disp.: 〈http://www.planalto.gov.br/ccivil_03/_Ato2015-2018/2016/Mpv/mpv746.htm>. Acesso em 14 jan. 2017.

. MEC. 2013a. Pacto Nacional pelo Fortalecimento do Ensino Médio. Disp.: <http://pactoensinomedio.mec. gov.br/ Acesso em 14 jan. 2017.

2013b. Programa Ensino Médio Inovador Documento Orientador. Disponível em: http://portal.mec.gov.br/ documentos/documento_orientador.pdf. Acesso em 14.01.2017.

2013c. Projeto de Lei 6.840, de 2013. Da Comissão Especial destinada a promover Estudos e Proposições para a Reformulação do Ensino Médio (CEENSI). Disponível em: http://www.camara.gov.br/proposicoesWeb/prop_ mostrarintegra?codteor=1200428\&filename=PL+6840/2013. Acesso em 14 jan. 2017.

; MEC/SEB.. 2013d. Formação de Professores do Ensino Médio: Ensino Médio e formação humana integral. Etapa I - Caderno I. Curitiba: Setor de Educação da UFPR, 2013.

; MEC/SASE. Planejando a próxima década: conhecendo as 20 metas do Plano Nacional de Educação. (MEC/SASE, 2014). Disponível em: www.pne.mec.gov.br. Acesso em 14 jan. 2017.

CARneIro, M. A. O Nó do Ensino Médio. Petrópolis, RJ: Vozes, 2012. 304p.

DAMIANI, M. F.; PORTO, T. M. E.; SCHLEMMER, E. (Orgs.) Trabalho colaborativo / cooperativo em educação: uma possibilidade para ensinar e aprender. São Leopoldo: Oikos; Brasília: Liber Livro, 2009,. 286p.

DEVÉS, E.V. El pensamiento latinoamericano en el siglo XX. Tomo II. Desde la CEPAL al neoliberalismo (19501990). Santiago: Editorial Biblos. Centro de Investigaciones Diego Barros Arana, 2003, 68p. Disponível em: <http://www.ucipfg.com/Repositorio/MGTS/MGTS14/MGTSV-05/semana5/complementarios/TDES_Deves_Valdes Unidad_1_1_.pdf>. Acesso em 18.01.017.

GATTI, B. Formação continuada de professores: a questão psicossocial. Cadernos de Pesquisa, n. 119, p. 191-204, julho/ 2003.

HERBERT, S. P. Orçamento participativo na perspectiva de Freire e Gramsci: condições para emergência e formação de lideranças. Porto Alegre: Redes Editora, 2008. 326p.

INEP. Censo escolar 2015. Disponível em: 〈www.inep.gov.br/resultados-2015>. Acesso em 14 jan. 2017.

KUENZER, A.Z. As políticas de formação: A constituição da identidade do professor sobrante. Educação \& Sociedade, ano XX, $\mathrm{n}^{\circ}$ 68, , p.61-79, dezembro/99. Disponível em: http://www.plataformademocratica.org/Publicacoes/17019_Cached.pdf. Acesso em 14.01.2017. 
KUENZER, A. Z. O Ensino Médio no Plano Nacional de Educação 2011-2020: superando a década perdida? Educação \& Sociedade, Campinas, v. 31, n. 112, p. 851-873, jul-set. 2010. Disp.: 〈http://www.cedes.unicamp.br〉. Acesso em 14 jan. 2017.

NÓVOA, A. Professores, Imagens do futuro presente. Lisboa: Educa, 2009. 41 p.

PAIVA, C F.L.; SILVA, J.M.A.P. As polêmicas faces do Ensino Médio. Revista Educação: Teoria e Prática. Rio Claro, vol. 23, n. 43, p. 44-61. Maio-Ago, 2013. Disponível em: http://base.repositorio.unesp.br/bitstream/handle/ 11449/107107/ISSN1981-8106-2013-23-43-44-61.pdf?sequence=1. Acesso em 14 jan. 2017.

RAVITCH, D. Vida e morte do grande sistema escolar americano: como os testes padronizados e o modelo de mercado ameaçam a educação. Trad. de Marcelo Duarte. Porto Alegre: Sulina, 2011, 318p.

ROCHA, M.; SALBEGO, J. Por uma educação política: diálogos possíveis entre Paulo Freire e Edward Said. P. $41-64$. In: FREITAS, A. S.; GHIGGI, G.; PEREIRA, T. I. (Orgs.) Paulo Freire: em diálogo com outros (as) autores (as). Passo Fundo: Méritos, 2004.

SANTOS, B.S. A Crítica da razão indolente: contra o desperdício da experiência. Para um novo senso comum: a ciência, o direito e a política na transição paradigmática. 4. ed. São Paulo: Cortez, 2002, 415p.

AVRITZER, L. Introdução: para ampliar o cânone democrático. 2002. In: (Org.). Democratizar a democracia: os caminhos da democracia participativa. Rio de Janeiro: Civilização Brasileira, 2002. 683p.

SCHÖN, D. Formar professores como profissionais reflexivos. In: NÓVOA, A. (Org.) Os Professores e sua formação. Lisboa: Dom Quixote, 1992. p.77-92.

WEYH, C. B. Educar pela participação. Santo Ângelo: FURI, 2011. 216p.

ZABALA, A. A prática educativa: como ensinar. Trad. Ernani F. F. Rosa. Porto Alegre: ArtMed, 1998. 224p. 


\section{RESUMO}

O artigo, de caráter bibliográfico e empírico, tem como tema o ensino médio brasileiro, enfocando a formação continuada dos professores como estratégia de permanência. 0 objetivo consiste em analisar estratégias de permanência, apresentando dados de professores de duas escolas sobre os encontros de formação do Pacto Nacional Ensino Médio, cujo objetivo era aumentar a permanência por meio de jornadas de formação. Os resultados mostram relação entre os docentes que não se dispuseram a participar da pesquisa e a descontinuidade das políticas educacionais. A totalidade dos entrevistados relaciona a formação continuada e a prática pedagógica, porém, o trabalho colaborativo mostrou-se um desafio. Conclui-se pela necessidade de pensar estratégias de permanência, a exemplo do Pacto, para potencializar a formação continuada dos professores, posto que os resultados apontam para uma significativa relação entre os dois aspectos.

Palavras-chave: Pacto Nacional do Ensino Médio. Formação continuada. Permanência escolar.

\section{THE PERMANENCE IN BRAZILIAN MIDDLE EDUCATION AND ITS RELATIONSHIP WITH TEACHER TRAINING}

\section{ABSTRACT}

The article, with a bibliographical and empirical character, has as its theme the Brazilian High School Teaching, focusing on the continued formation of teachers as a strategy of permanence. It aims to analyze permanence strategies, presenting data from teachers from two schools about the formation meetings of the National High School Pact, whose objective was to increase the permanence through training journeys. The results show a relationship among: teachers who were not willing to participate in the research and the discontinuity of educational policies; continuing education and pedagogical practice and the challenge of collaborative work. It is concluded that there is a need to think about continuance strategies in secondary education, as in the case of the Pact, in order to foster the continuous formation of teachers, since the results point to a significant relationship between the two.

Keywords: National Pact for Secondary Education. Continued Faculty Education. School Remain. 